\title{
Water quality analysis at Javary Lake, Rio de Janeiro, Brazil
}

\author{
M. M. Veiga \& D. M. Silva \\ Environmental Health Department, National School of Public Health, \\ Oswaldo Cruz Foundation, Ministry of Health, Brazil
}

\begin{abstract}
Historically, Brazil has suffered from a lack of sanitation infrastructure. Only $42 \%$ of all domestic sewage is collected and less than one-third of the sewage collected receives any treatment before final discharge into water bodies. However, these are just the country's average numbers. In most small Brazilian towns the sanitary situation is even worse.

This two-year study analyzed the water quality in Javary Lake, which is the major leisure site for a small tourist municipality located in the mountain region of Rio de Janeiro state, in southeastern Brazil. This water resource has been progressively polluted over many decades due to raw domestic sewage discharges from local residences.

In the preliminary phase, we analyzed various parameters in water samples collected from 10 selected points along the shoreline, following the Standard Methods procedures: $\mathrm{pH}$; conductivity; dissolved oxygen (DO); salinity; dissolved solids; biochemical oxygen demand (BOD); chemical oxygen demand (COD); and nitrates. The preliminary results confirmed that Javary Lake is highly eutrophized and polluted with organic materials.

In the second phase, we analyzed the nature of the organic materials through coliform bacteria analysis. The results indicated that at 7 out of the 10 selected points the water quality was poor because of high raw sewage content.

In fact, the dissolved oxygen levels were similar to those found in facultative lagoons, a type of stabilization pond commonly used for biological wastewater treatment, which have to be drained every 20 to 30 years to maintain their treatment capability.

Javary Lake is intensely used by tourists and the local population, for fishing, swimming and boating, among other recreational activities, as well as for animal
\end{abstract}


watering. The overall findings of this study highlight that Javary Lake poses a serious threat to the health of tourists and the local community due to its continuous process of degradation and sludge sedimentation, which leads to cyanobacteria proliferation and anaerobiosis.

Keywords: water quality, sanitation, Brazilian legislation, Brazil.

\section{Introduction}

The World Health Organization (WHO) stresses the close relationship between health and sanitation. The lack of adequate systems for water supply, sewage collection and treatment and trash disposal directly affects the health of the population and the entire ecosystem. Indeed, a large percentage of diseases afflicting developing countries can be related to poor water quality. For this reason, proper collection and treatment of sewage is one of the most efficient measures to improve human and environmental health.

In Brazil, due to the lack of adequate sewage collection and treatment systems it is common for untreated domestic and/or industrial effluents to be discharged into water bodies. This often occurs through clandestine release of sewage into storm drain systems. As can be imagined, this situation has been causing serious problems to human health as well as to the environmental quality of rivers, lakes, lagoons, bays and offshore waters.

The municipality of Miguel Pereira, where Javary Lake is located, has a population of around 30,000 and a total area of $288.8 \mathrm{~km}^{2}$. Because of its location in the high mountains inland of the state of Rio de Janeiro, its climate is cooler than on the coast, making it a popular tourist destination, especially in the hot summer months. The municipality of Miguel Pereira has an urbanization rate of $84.0 \%$ and has three towns, Miguel Pereira proper, Conrado and Governador Portela. The town of Governador Portela accounts for 32\% of the municipal population and is the principal source of pollution of Javary Lake, which is the main tourist attraction in the region. It has a shoreline of slightly over $2 \mathrm{~km}$. The watershed containing Javary Lake covers $3.74 \mathrm{~km}^{2}$. Besides its relevance for recreational activities, the lake is important for its scenic beauty, drainage and ecological impact on the region.

Despite its importance, the lake has been progressively polluted over the decades, mainly by discharge of domestic sewage. In the municipality, $24.6 \%$ of dwellings have piped water, $73.7 \%$ obtain their water from wells or springs and the remaining $1.7 \%$ get their water from other sources. The municipal sewer collection system only serves $13.5 \%$ of the dwellings, while $65.3 \%$ have proper septic tanks, $10.7 \%$ use rudimentary septic pits, $7.5 \%$ are connected to uncovered ditches and $2.5 \%$ discharge their sewage directly into a water body. None of the sewage collected receives treatment before discharge into water bodies [1].

The result of this lack of sewage treatment was reflected in the findings of this study, which revealed various problems of environmental health in the region, mainly associated with raw sewage. The physical-chemical and microbiological analyses performed showed that the lake is polluted mainly by 
organic matter (domestic sewage). However, the $\mathrm{COD} / \mathrm{BOD}$ ratio at some sampling points did not rule out the possibility of contamination by industrial wastewater.

\section{Materials and methods}

The objective of this study was to assess the environmental quality of Javary Lake, located in southeastern Brazil. In 2007 and 2008 we collected water samples from 10 points along the entire shoreline (Figure 1). These points were selected based on accessibility, coverage and relevance.

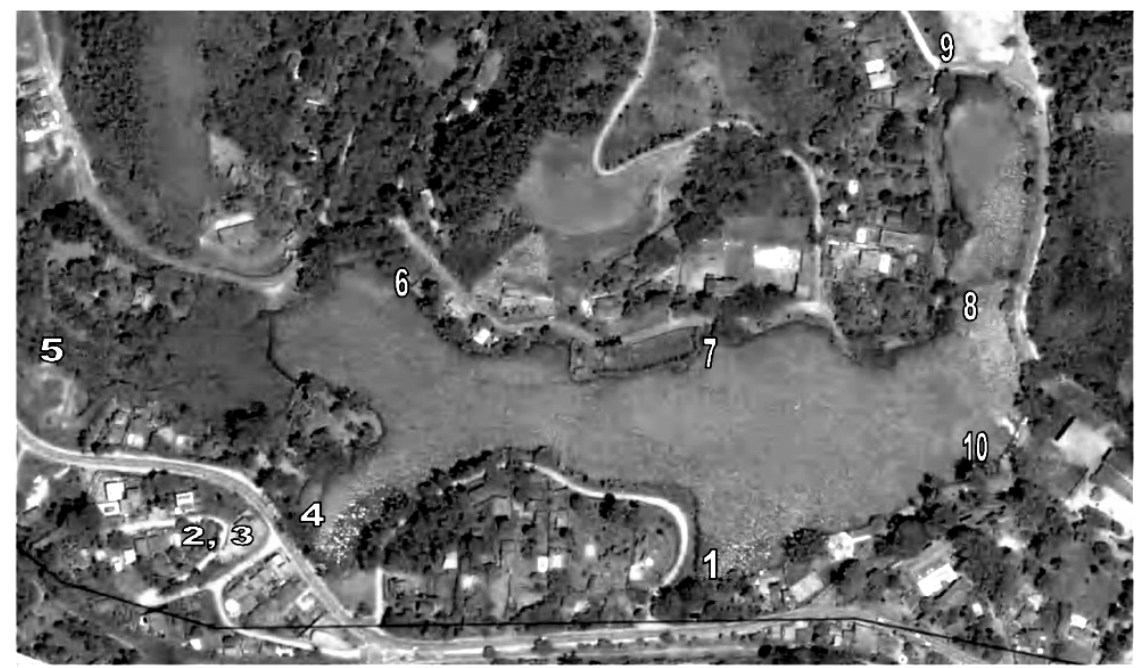

Figure 1: Aerial view of Javary Lake with indication of the 10 sampling points. Source: [4].

In the first step of the analysis, we collected six samples each from the ten 10 points, to assess $\mathrm{pH}$, conductivity, dissolved oxygen, salinity and total dissolved solids, using a Hanna Instruments model HI-9828 multiparameter water quality meter for analysis in the field. We then took the remainder of these samples to the laboratory to evaluate the $\mathrm{COD}, \mathrm{BOD}$ and nitrates, according to the procedure recommended in the Standard Methods [2, 3].

The results of these first analyses indicated the presence of high levels of organic materials. For this reason, we designed a second step to assess the characteristics of this organic load in more detail, by analyses of thermotolerant (fecal) coliforms and total coliforms using ChromoCult ${ }^{\circledR}$ coliform agar (Merck). 


\section{Results}

In The results of the first step showed a worrying degradation of the water quality of Javary Lake. The results of the analyses indicated the contamination consisted mainly of organic material, possibly from domestic sewage, causing serious eutrophication of the lake.

According to Resolution 357/2005 [5] from the Brazilian National Environmental Council (CONAMA), water intended for human consumption after conventional or advanced treatment, as well as for irrigation of crops that will not be eaten raw, sport fishing, recreation with secondary contact (partial body contact, such as boating) and watering of animals is categorized in class 3 . The highest allowable BOD5 level for this class of water is $10 \mathrm{mg} / \mathrm{l}$. As can be seen from Table 1 below, virtually all the water samples exceeded this threshold. Only the samples from point 9 were below this level.

\section{Table 1: $\quad$ BOD results.}

\begin{tabular}{|c|c|c|c|c|c|c|}
\hline \multicolumn{7}{|c|}{ BOD $_{5}-$ in mg/1 } \\
\hline Point & \multicolumn{7}{|c|}{ Collection } \\
\hline & 1 st & 2nd & 3rd & 4th & 5 th & 6 th \\
\hline 1 & $17+/-1$ & $17+/-0$ & $22+/-1$ & $20+/-0$ & $25+/-1$ & $21+/-0$ \\
\hline 2 & $91+/-10$ & $95+/-1$ & $164+/-4$ & $43+/-1$ & $83+/-1$ & $90+/-1$ \\
\hline 3 & $136+/-11$ & $95+/-6$ & $154+/-4$ & $123+/-6$ & $126+/-3$ & $133+/-2$ \\
\hline 4 & $23+/-1$ & $25+/-0$ & $15+/-0$ & $13+/-1$ & $11+/-1$ & $14+/-0$ \\
\hline 5 & $53+/-5$ & $25+/-3$ & $51+/-2$ & $38+/-2$ & $65+/-3$ & $69+/-2$ \\
\hline 6 & $14+/-0$ & $11+/-0$ & $21+/-1$ & $16+/-1$ & $23+/-1$ & $17+/-1$ \\
\hline 7 & $17+/-0$ & $14+/-0$ & $23+/-1$ & $14+/-0$ & $23+/-1$ & $19+/-1$ \\
\hline 8 & $16+/-0$ & $22+/-1$ & $24+/-0$ & $16+/-1$ & $28+/-0$ & $18+/-0$ \\
\hline 9 & $11+/-2$ & $5+/-0$ & $8+/-1$ & $8+/-0$ & $9+/-1$ & $7+/-1$ \\
\hline 10 & $15+/-0$ & $20+/-0$ & $23+/-1$ & $13+/-1$ & $22+/-1$ & $18+/-1$ \\
\hline
\end{tabular}

However, the water in Javary Lake should be considered as being in class 1 or 2 , due to its use by tourists and residents for activities involving primary contact (full body contact, such as swimming and wading). In these cases, CONAMA Resolution 357/2005 sets the maximum BOD5 limits at 3 and $5 \mathrm{mg} / \mathrm{l}$, respectively. All the sample values were above these limits and some of them were well above $100 \mathrm{mg} / \mathrm{l}$, which is typical of weak domestic sewage. The values found demonstrate that the organic load, introduced by raw sewage discharge, exceeds the lake's capacity for dilution and biodegradation, which is low because it is a lentic body.

The COD values (Table 2) and the COD/BOD ratio (Table 3) in most cases also indicated the introduction of industrial wastes. Although there are no industrial activities in the region, there are various commercial establishments that produce effluents with industrial characteristics, such as car repair shops, lumber yards, service stations and cabinet making shops. Besides the high COD values, the COD/BOD ratios greater than 2.4 (shaded in Table 3) are associated 
Table 2: $\quad$ COD results.

\begin{tabular}{|c|c|c|c|c|c|c|}
\hline \multicolumn{7}{|c|}{ COD- in mg/l } \\
\hline Point & \multicolumn{7}{|c|}{ Collection } \\
\hline & 1 st & 2nd & 3rd & 4th & 5 th & 6 th \\
\hline 1 & 90 & 88 & 89 & 69 & 83 & 69 \\
\hline 2 & 136 & 183 & 714 & 87 & 86 & 87 \\
\hline 3 & 279 & 59 & 73 & 88 & 89 & 88 \\
\hline 4 & 81 & 81 & 51 & 41 & 34 & 41 \\
\hline 5 & 65 & 70 & 34 & 35 & 56 & 35 \\
\hline 6 & 89 & 89 & 90 & 59 & 80 & 59 \\
\hline 7 & 91 & 89 & 89 & 63 & 70 & 63 \\
\hline 8 & 90 & 90 & 87 & 68 & 79 & 68 \\
\hline 9 & 34 & 22 & 16 & 46 & 21 & 46 \\
\hline 10 & 90 & 89 & 89 & 63 & 76 & 63 \\
\hline
\end{tabular}

Table 3: $\quad$ BOD/COD ratio.

\begin{tabular}{|c|c|c|c|c|c|c|}
\hline \multicolumn{7}{|c|}{ COD/BOD Ratio } \\
\hline Point & \multicolumn{7}{|c|}{ Collection } \\
\hline & 1st & 2nd & 3rd & 4th & 5th & 6th \\
\hline 1 & 5.29 & 5.18 & 4.05 & 3.45 & 3.32 & 3.29 \\
\hline 2 & 1.49 & 1.93 & 4.35 & 2.02 & 1.04 & 0.97 \\
\hline 3 & 2.05 & 0.62 & 0.47 & 0.72 & 0.71 & 0.66 \\
\hline 4 & 3.52 & 3.24 & 3.40 & 3.15 & 3.09 & 2.93 \\
\hline 5 & 1.23 & 2.80 & 0.67 & 0.92 & 0.86 & 0.51 \\
\hline 6 & 6.36 & 8.09 & 4.29 & 3.69 & 3.48 & 3.47 \\
\hline 7 & 5.35 & 6.36 & 3.87 & 4.50 & 3.04 & 3.32 \\
\hline 8 & 5.63 & 4.09 & 3.63 & 4.25 & 2.82 & 3.78 \\
\hline 9 & 3.09 & 4.40 & 2.00 & 5.75 & 2.33 & 6.57 \\
\hline 10 & 6.00 & 4.45 & 3.87 & 4.85 & 3.45 & 3.50 \\
\hline
\end{tabular}

with the presence of industrial wastes, because for domestic sewage the ratio is between 1.7 and 2.4 [3].

High nitrate levels, as shown in Table 4, are associated with the occurrence of eutrophication. Water with nitrate concentration above $10 \mathrm{mg} / 1$ is considered unfit for human consumption. This is the maximum value permitted for classes 1, 2 and 3 according to CONAMA Resolution 357/2005 [5]. Only two values (shaded) were lower than $10 \mathrm{mg} / \mathrm{l}$. The levels found indicate decomposition of the organic matter introduced into the lake through sewage discharge, again aggravated by the fact it is a lentic body. Such water bodies generally require removal of nutrients (nitrogen and phosphorous) through sewage treatment to reduce eutrophication.

We also performed various analyses of thermotolerant and total coliforms to check for compliance with the applicable national regulations (CONAMA Resolution 274/2000). The thermotolerant coliform values found were all greater than the maximum level (satisfactory category) permitted for human 
consumption, which is 1,000 coliforms per $100 \mathrm{ml}$. These results demonstrated that the water in Javary Lake was highly contaminated and unfit for human recreation with primary contact.

Among the parameters analyzed with the multiparameter water quality meter, the dissolved oxygen was particularly high, indicating intense production of oxygen by algae. This high dissolved oxygen concentration inhibits the occurrence of unpleasant odors, typical of anaerobic environments, and favors biodegradation of organic matter.

However, the high eutrophication can provide favorable conditions for algal blooms, which contaminate the water with cyanotoxins. The dissolved oxygen concentrations shown in Table 4 are similar to those observed in facultative lagoons, which are constructed specifically for sewage treatment. These lagoons normally need to be drained and dredged every 20 or 30 years to maintain their volume and treatment capacity. Therefore, what is likely happening in Javary Lake is a process of sedimentation, which can lead to future anaerobiosis.

Table 4: $\quad \mathrm{NO}_{3}{ }^{-}$results.

\begin{tabular}{|c|c|c|c|c|c|c|}
\hline \multicolumn{7}{|c|}{$\mathrm{NO}_{3}{ }^{-}-$in mg/l } \\
\hline Point & \multicolumn{7}{|c|}{ Collection } \\
\hline & 1st & 2nd & 3rd & 4th & 5th & 6th \\
\hline 1 & 42.36 & 70.34 & 79.96 & 55.40 & 58.73 & 3.50 \\
\hline 2 & 90.61 & 370.50 & 160.14 & 223.05 & 255.96 & 292.26 \\
\hline 3 & 125.74 & 410.84 & 260.82 & 312.68 & 351.41 & 377.54 \\
\hline 4 & 35.81 & 58.64 & 83.68 & 55.40 & 75.74 & 196.52 \\
\hline 5 & 23.73 & 297.62 & 107.24 & 24.56 & 83.02 & 379.15 \\
\hline 6 & 24.85 & 17.69 & 52.88 & 62.52 & 55.17 & 83.35 \\
\hline 7 & 28.07 & 44.27 & 57.92 & 78.63 & 70.55 & 62.89 \\
\hline 8 & 18.36 & 367.45 & 109.48 & 12.14 & 76.69 & 56.28 \\
\hline 9 & 40.62 & 85.77 & 81.63 & 103.98 & 128.09 & 110.93 \\
\hline 10 & 20.74 & 8.69 & 23.13 & 87.64 & 73.56 & 53.47 \\
\hline
\end{tabular}

In the second phase of the study we analyzed the total and thermotolerant coliform levels to assess the characteristics of this organic load. Total coliforms are defined as the group of all Gram-negative, aerobic or anaerobic, non-spore forming, oxidase-negative bacilli capable of growing in the presence of bile salts or other active surface (surfactant) compounds, with similar growth-inhibition properties and that ferment lactose and produce aldehyde, acid and gas at $35^{\circ} \mathrm{C}$ in 24-48 hours. This group includes organisms that differ in their biochemical and serological characteristics and habitats. It includes the following genera: Escherichia, Citrobacter, Enterobacter and Klebsiella, as well as others that almost never appear in feces, such as Serratia.

In contrast, thermotolerant coliforms are capable of growing and fermenting lactose, with the production of acid and gas, at a temperature of $44.5 \pm 0.2{ }^{\circ} \mathrm{C}$ in 24 hours. The main component of this group is Escherichia coli, although some coliforms of the Klebsiella genus also have this capacity.

The presence of coliform bacteria has been extensively used to assess water quality. Their levels serve as a basic microbiological parameter, as indicators of 
fecal pollution, because they are always present in the intestinal tract of humans and other warm-blooded animals and are eliminated in large quantities in the feces. Hence, these levels are included in the water quality regulations of many countries, including Brazil. The presence of coliforms in water indicates pollution, with a risk of the presence of pathogenic organisms, since they are more resistant in water than pathogenic bacteria of intestinal origin.

Therefore, we also carried out various analyses of thermotolerant and total coliforms to check for compliance with the applicable regulations (CONAMA Resolutions 274/00 and 357/05) [5,6]. The results are shown in Table 5. The levels of thermotolerant coliforms per $100 \mathrm{ml}$ found were much higher than the maximum concentration (satisfactory category) permitted by these regulations, which is 1,000 coliforms per $100 \mathrm{ml}$. This finding demonstrates that the lake's water is highly contaminated and unfit for recreation where there is the possibility of primary contact.

Table 5: $\quad$ Fecal coliforms.

\begin{tabular}{|c|c|c|c|c|c|c|}
\hline \multicolumn{7}{|c|}{ Fecal Coliform Colonies per 100 ml } \\
\hline Point & \multicolumn{7}{|c|}{ Collection } \\
\hline & 1 st & 2nd & 3rd & 4th & 5 th & 6th \\
\hline 1 & 26,000 & 28,000 & 81,000 & 2,300 & 2,000 & 8,000 \\
\hline 2 & 12,000 & 11,000 & 1,000 & 1,200 & $>300,000$ & 43,000 \\
\hline 3 & 20,000 & 25,000 & 25,000 & 120 & 27,000 & 20,000 \\
\hline 4 & 102,000 & 94,000 & $>30,000$ & 8,000 & 6,000 & 1,100 \\
\hline 5 & $>300,000$ & 11,000 & 7,000 & 2,200 & 12,000 & 17,000 \\
\hline 6 & $>3,000$ & 160 & 400 & 300,000 & 400 & 17,000 \\
\hline 7 & 120 & 40 & 120 & 120 & 160 & $>3,000$ \\
\hline 8 & $>3,000$ & 80 & 180 & 80 & 60 & 200 \\
\hline 9 & 700 & $>3,000$ & $>3,000$ & 20,000 & 590 & 1,800 \\
\hline 10 & 90 & 100 & 240 & 3,000 & 60 & 8,000 \\
\hline
\end{tabular}

Resolution 357/05 [5] establishes the water quality conditions through limits for thermotolerant coliforms. For class 3 fresh water, which is considered suitable for recreation with secondary contact, the limit is 2,500 thermotolerant coliforms per $100 \mathrm{ml}$. For watering of animals raised in confined spaces, this limit is 1,000 coliforms per $100 \mathrm{ml}$, and for other uses the limit is 4,000 coliforms.

As can be seen from the shaded figures in Table 5, the results were within the legal limits for class 2 fresh water at only three sampling points, all located near the central part of the lake. Probably this location allowed greater dilution. The other values found can be characterized as indicating environmental contamination typical of "strong sewage".

The levels of dissolved oxygen (DO) and saturation percentage in the two collections where these parameters were analyzed, presented very wide variation. The saturation ranged from 0.84 to $11.94 \%$. Very low values, near zero, are associated with anaerobic conditions at the lake bottom, and very high ones, near the saturation value, are associated with the presence of algae, and hence of 
eutrophic conditions. Fish cannot live in water with levels below $3 \mathrm{mg} / \mathrm{l}$, and freshwater fish typically require DO levels above $5 \mathrm{mg} / \mathrm{l}$. According to CONAMA Resolution 357/2005 [5], class 1 and 2 fresh water bodies must have DO levels of at least 6 and $5 \mathrm{mg} / \mathrm{l}$, respectively.

As can be seen in Table 6, the DO levels in the water samples from the first collection were very high, above the saturation value, indicating the presence of algae and a eutrophic condition. In the second collection, none of the values obtained satisfied the legal requirements for classes 1 and 2. In fact, the values obtained in Javary Lake did not even meet the requirement for class 4, which is water after the discharge of treated sewage.

The $\mathrm{pH}$ values of a water body are associated with the corresponding $\mathrm{pH}$ levels of the soil in its drainage area, the sediment in its bed, the rainwater that falls in the area and the effluents flowing into it, as well as of the presence of algae. The discharge of domestic sewage tends to lower the $\mathrm{pH}$ level of water bodies. On the other hand, the presence of algae tends to raise the $\mathrm{pH}$ values because they consume carbonate to multiply. The combination of these antagonistic effects helps explain the great variability of the $\mathrm{pH}$ values found, which ranged between 6.57 and 10.11. In aerobic or facultative sewage treatment lagoons, the $\mathrm{pH}$ values are generally above 8 , the same as for eutrophized water bodies.

In general, the points with the highest DO concentrations also had high $\mathrm{pH}$ levels. The wide variation of the $\mathrm{DO}$ and $\mathrm{pH}$ values can indicate a seasonal pattern in the amount of sewage discharged into Javary Lake. There are other pertinent factors to be considered as well, such as dilution by rainfall, temperature and the degree of insolation, among other environmental variables.

Dissolve Oxygen Percent Saturation values between 80 and $120 \%$ are considered excellent. DO values of less than $60 \%$ or over $125 \%$ are considered to be poor. Supersaturated percentage of DO (shaded in Table 6) can be harmful to fish and other aquatic organisms.

Table 6: Dissolved oxygen (DO), saturation percentage and $\mathrm{pH}$ results.

\begin{tabular}{|c|c|c|c|c|c|c|}
\hline \multicolumn{7}{|c|}{ DO (mg/l), saturation percentage and $\mathrm{pH}}$. \\
\hline Point & \multicolumn{7}{|c|}{ Collection } \\
\hline & & & & 2nd \\
\hline & DO & Sat. \% & $\mathrm{pH}$ & $\mathrm{DO}$ & Sat. \% & $\mathrm{pH}$ \\
\hline 1 & 6.65 & 87.3 & 9.11 & 2.74 & 34.8 & 7.40 \\
\hline 2 & 1.46 & 19.5 & 7.46 & 2.60 & 32.4 & 7.07 \\
\hline 3 & 3.41 & 44.3 & 7.67 & 2.43 & 30.2 & 7.31 \\
\hline 4 & 3.87 & 52.4 & 7.38 & 0.84 & 10.2 & 6.57 \\
\hline 5 & 0.86 & 10.9 & 7.15 & 2.30 & 27.9 & 7.05 \\
\hline 6 & 4.46 & 58.6 & 9.01 & 2.06 & 26.3 & 7.60 \\
\hline 7 & 6.93 & 90.9 & 9.55 & 1.47 & 19.0 & 7.90 \\
\hline 8 & 11.94 & 162.1 & 10.11 & 2.70 & 34.9 & 8.41 \\
\hline 9 & 3.77 & 51.3 & 7.10 & 3.48 & 43.2 & 8.07 \\
\hline 10 & 9.73 & 130.3 & 9.93 & 1.89 & 24.0 & 7.98 \\
\hline
\end{tabular}


Table 7: $\quad$ Total ammonia nitrogen.

\begin{tabular}{|c|c|c|c|c|c|c|}
\hline \multicolumn{7}{|c|}{$\mathrm{N}-\mathrm{NH}_{3}-$ in $\mathrm{mg} / \mathrm{l}$. } \\
\hline Point & & & & & & \\
\hline & $1 \mathrm{st}$ & 2nd & $3 \mathrm{rd}$ & 4th & 5 th & 6th \\
\hline 1 & 2.16 & 0.70 & 1.37 & 1.40 & 0.68 & 2.98 \\
\hline 2 & 108.93 & 20.46 & 17.74 & 6.79 & 14.96 & 18.08 \\
\hline 3 & 112.67 & 20.63 & 18.11 & 7.86 & 15.54 & 19.03 \\
\hline 4 & 74.45 & 13.51 & 4.98 & 2.16 & 3.05 & 3.22 \\
\hline 5 & 85.74 & 14.36 & 14.89 & 6.33 & 11.69 & 13.65 \\
\hline 6 & 2.32 & 0.46 & 0.09 & 1.13 & 0.47 & 0.21 \\
\hline 7 & 2.15 & 0.09 & 0.06 & 0.70 & 0.49 & 0.17 \\
\hline 8 & 1.90 & 0.10 & 0.06 & 0.59 & 0.32 & 0.14 \\
\hline 9 & 13.31 & 2.63 & 1.61 & 0.72 & 0.69 & 0.63 \\
\hline 10 & 1.55 & 0.10 & 0.39 & 0.61 & 0.29 & 0.10 \\
\hline
\end{tabular}

Some of the total ammonia nitrogen values, presented in Table 7, were very high, again not meeting the legal limits (CONAMA Resolution 357/2005) [5], whose upper limits are presented in Table 8. Some of these values (shaded) even exceeded those typical of raw sewage, of 20 to $40 \mathrm{mg} / \mathrm{l}$ [7].

These findings are probably due to the decomposition of organic material, which is converted first into ammonia, and to the process of accumulation of nutrients, aggravated because of the lake's lentic nature.

However, some of the figures were low enough to satisfy CONAMA Resolution 357/2005 [5]. These probably resulted from the hydrodynamics and the decomposition process that occurs in Javary Lake. At some points, farther from where sewage flows into the lake, the processes of sedimentation, decomposition, dilution, mixture and circulation appears to alleviate the contamination by ammonia nitrogen.

The concentration of NH3 (free ammonia) toxic to fish and other aquatic organisms is determined by the level of $\mathrm{pH}$. For $\mathrm{pH}$ values lower than 8 , practically all the ammonia is in the form of $\mathrm{NH} 4+$ (which is less toxic); for $\mathrm{pH}$ equal to 9.5, half the ammonia is in the form of NH3 and the other half in the form of NH4; and for $\mathrm{pH}$ above 11, practically all the ammonia is in the form of

Table 8: Maximum levels of total ammonia nitrogen, according to CONAMA resolution 357/2005 [5].

\begin{tabular}{|c|c|c|}
\hline \multicolumn{3}{|c|}{ 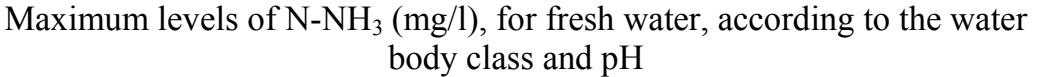 } \\
\hline $\mathrm{pH}$ & Ciasses 1 and 2 & Class 3 \\
\hline $\mathrm{pH} \leq 7.5$ & 3.7 & 13.3 \\
\hline $7.5>\mathrm{pH} \geq 8.0$ & 2.0 & 5.6 \\
\hline $8.0>\mathrm{pH} \geq 8.5$ & 1.0 & 2.2 \\
\hline $\mathrm{pH}>8.5$ & 0.5 & 1.0 \\
\hline
\end{tabular}


NH3. Based on the ammonia and pH values in Javary Lake, the ammonia levels pose a substantial risk to fish, because the highest levels of total ammonia nitrogen were obtained at points where the $\mathrm{pH}$ values were low (below 8).

\section{Conclusions}

Javary Lake is the main recreational and scenic attraction of the municipality of Miguel Pereira, forming a cornerstone of the local tourist-based economy, and is also intensely used by the local population for leisure and stock-raising activities (animal watering). However, the gradual degradation of its water quality over the past decades threatens to undermine this economic value and also poses a serious risk to human health.

The results presented in this article, based on physical-chemical and microbiological analyses, show that the lake is mainly polluted by organic material (domestic sewage). However, the COD/BOD ratios at some sampling points indicated the possibility of contamination by industrial effluents as well.

In the fecal coliform analyses, the results were below the maximum value allowed by Brazilian environmental regulations at only three points, all located along the central part of the shoreline. At some points the contamination found was so severe that it could be characterized as typical of "strong sewage".

Among the parameters analyzed with the multiparameter water quality meter, the very high levels of dissolved oxygen stand out. These levels indicate intense production of oxygen by algae. High oxygen concentration impedes the occurrence of offensive odors, typical of anaerobic environments, and favors biodegradation of organic material, but high eutrophication can lead to algal blooms and consequent contamination by cyanotoxins. Despite the wide variation, in some cases the dissolved oxygen concentrations were similar to those observed in facultative lagoons, which are ponds formed specifically for waste treatment.

The results of this study indicate a worrying deterioration of the water quality in Javary Lake. The contamination found mainly came from the organic load, possibly from the discharge of untreated domestic sewage, causing severe eutrophication of the lake.

Therefore, it appears that over the years Javary Lake has suffered from eutrophication combined with a process of sedimentation and deposition of sludge and mud, which can even lead to a future condition of anaerobiosis. To reverse this situation, it is necessary not only to build an efficient waste treatment system, but also to dredge the lake bottom to remove the accumulation of contaminated sludge and mud.

\section{References}

[1] Rio de Janeiro Auditing Authority (TCE). Socioeconomics Study 2005 (in portuguese). Miguel Pereira. www.tce.rj.gov.br (jul/08). Rio de Janeiro, RJ. 2008 
[2] Standard Methods (SM). American Public Health Association (APHA), the American Water Works Association (AWWA), and the Water Environment Federation (WEF). Standard Methods for the Examination of Water and Wastewater. $21^{\circ}$ Ed. 2005.

[3] Metcalf \& Eddy. Wastewater Engineering. Treatment and Reuse. 4 ed. McGraw-Hill Ed. 2006.

[4] Google Earth: http:// http://www.google.com/earth/index.html, access in January 2009.

[5] CONAMA (National Council for the Environment). Resolution 357/2005 issued on 17/03/2005. Classification of water resources and establish discharge standards.

[6] CONAMA (National Council for the Environment). Resolution 274/2000 issued on 29/11/2000. Establish water quality standards.

[7] Von Sperling, Marcos. Introduction to water quality and wastewater treatment (in Portuguese). Vol.1, $3^{\text {a }}$ Ed. Ed. DESA. 2005. 